\section{SSC detector collaborators shun financial commitment}

\begin{abstract}
Washington, London \& Japan. US scientists responsible for building one of the two large detectors for the Superconducting Super Collider (SSC) in Texas are counting on money from other countries that is unlikely to materialize, according to government officials in Europe, North America and Asia. At the same time, the fate of the \$10-billion proton-proton accelerator appears to rest with President Bill Clinton's willingness to
\end{abstract} persuade a reluctant US Congress to continue its funding.

The Solenoid Detector Collaboration (SDC) is a $\$ 589$ million project involving the United States and seven other countries Britain, Canada, China, France, Italy, Japan and Russia (see Nature 357, 102; 1992). The United States is expecting those countries to finance nearly 40 per cent - some $\$ 231$ million - of the detector, which contains a vast array of equipment and electronics needed to record and interpret the results of hundreds of millions of collisions a second. At present, SSC documents refer only to "expected participation" by other countries at a level equal to what it would cost to build a particular piece of equipment in the United States (see table).

None of the seven countries, each of which faces the same budgetary pressures that have led the United States to seek outside support, has made a commitment to pay its share. But SSC officials, ever optimistic, expect each team of collaborating scientists to submit a request to the appropriate funding agency in its country and to win approval over the next $12-18$ months to keep on schedule for completion in 1999.

But that seems unlikely to happen. At best, individual scientists now collaborating with the SSC laboratory on generic detector research say that they may at some point ask for money, but none is confident of success.

Most European countries, scheduled for contributions of roughly $\$ 15$ million, support a similar machine - the Large Hadron Collider (LHC) - still in the planning stages at CERN, the European Laboratory for Particle Physics in Geneva. The Japanese, expected to contribute half - $\$ 116$ million - of the overall foreign share, have repeatedly avoided any commitment to the SSC or the SDC. A US-Japanese working group set up last year has not met since the US presidential election, although the issue is expected to be raised later this month when Prime Minister Kiichi Miyazawa meets Clinton in Washington.

The Canadians, in contrast, strongly favour the SSC, but the country's annual budget for high-energy physics is less than the $\$ 25$ million needed for the SDC. The Russians, expected to contribute $\$ 33$ million, welcome foreign contributions to their cash-starved scientific system but have little money to spend. The Chinese contribution of $\$ 10$ million, the smallest of all, appears the one most likely to materialize.

Roy Schwitters, director of the SSC laboratory in Texas, discussed the subject earlier this year with more than two dozen foreign science attachés based in Washington. His comments about potential contributions to the SDC appear to have shocked or amused many in his audience.

"I was astonished to hear reports [of what Schwitters said] because there is no commitment to spend any money on the SSC", says Sir Mark Richmond, chairman of the UK Science and Engineering Research Council. "If I had \$15 million to spend in this way, I would spend it on the LHC."

Roger Cashmore, a physicist at the University of Oxford and head of the four British teams involved in the SDC, explains that the $\$ 15$ million represents "the maximum viable contribution that would also make sense scientifically while not exceed-

ing 10 per cent of Britain's potential contribution to the LHC". But no request has been submitted, Cashmore says.

Claude Wolff, French science attaché and organizer of the meeting, says that "I am not aware of any request" for the estimated $\$ 13.7$ million and that the French scientists now working on the SDC are being paid by the SSC, not the other way around. An official of the Centre National de la Recherche Scientifique(CNRS) says that the French government would need to triple its research budget to provide "any money at all".

The Canadian team, headed by Bob Ott of the University of Toronto, expects to submit a proposal later this year to fund parts of two pieces of equipment that some two dozen Canadian physicists want to develop. The group hopes to receive money from three government agencies, in particular the National Science and Engineering Research Council which has provided C\$1.25 million over two years for preliminary work.

Although the $\mathrm{Ca}$ nadians believe that the SDC is far superior to the $\mathrm{LHC}$, the government will be hard-pressed to find the money. An advisory panel on nuclear and particle physics has been told to

assume a flat budget for the field, which Ott calls "a disaster scenario", but he remains hopeful that some money will be found to continue the US collaboration.

In Japan, a \$12-million programme for collaborative research on a range of US high-energy physics projects includes generic research on the SDC. But Takahiko Kondo of KEK, Japan's National Laboratory for High-Energy Physics, says that there has been no official request for $\$ 116$ million and that the figure neither corresponds to actual construction costs in Japan nor includes the infrastructure needed to build the superconducting coil and other important features of the detector.

Meanwhile, the fate of a \$640-million request to the US Congress for the SSC in the fiscal year that begins on 1 October could hinge on the extent of support offered by the president. "If the president puts his full weight behind it, we'll be OK and you'll start to see some of the other countries fall in line", says William Happer, director of the Office of Energy Research at the US Department of Energy. "If not, it's a foregone conclusion that the SSC will be killed."

Jeffrey Mervis, David Dickson \& David Swinbanks 